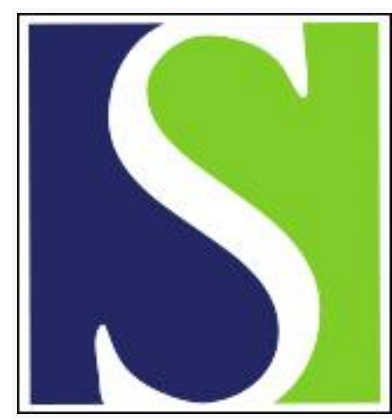

Scand J Work Environ Health 2008;34(6):430-437

https://doi.org/10.5271/sjweh.1289

Issue date: 00 Dec 2008

Influence of self-reported work conditions and health on full, partial and no return to work after long-term sickness absence

by Josephson $M$, Heijbel $B$, Voss $M$, Alfredsson L, Vingård $E$

Affiliation: Occupational and Environmental Medicine, Uppsala University, Akademiska sjukhuset, 75185 Uppsala, Sweden. Malin.Josephson@medsci.uu.se

Refers to the following text of the Journal: 1997;23(2):130-139

The following articles refer to this text: $2009 ; 35(4): 241-243$;

2010;36(4):332-338; 2010;36(6):473-483; 2010;36(6):515-516; 2013;39(1):37-45

Key terms: full return to work; health; long-term sickness absence; partial return to work; partial sick leave; psychosocial work conditions; questionnaire; return to work; self-assessment; self-report; self-reported work conditions; sick leave; work conditions

This article in PubMed: www.ncbi.nlm.nih.gov/pubmed/19137204 


\title{
Influence of self-reported work conditions and health on full, partial and no return to work after long-term sickness absence
}

\author{
by Malin Josephson, PhD, ${ }^{1}$ Bodil Heijbel, MD, ${ }^{1,2}$ Margaretha Voss, PhD, ${ }^{2}$ Lars Alfredsson, PhD,, 4 \\ Eva Vingård, $M D^{1}$
}

\begin{abstract}
Josephson M, Heijbel B, Voss M, Alfredsson L, Vingård E. Influence of self-reported work conditions and health on full, partial and no return to work after long-term sickness absence. Scand J Work Environ Health 2008;34(6):430-437.
\end{abstract}

\begin{abstract}
Objectives This study aimed at describing the frequency of full, partial, and no return to work after long-term sick leave and at ascertaining the influence of psychosocial work conditions, work ability and health, reported before the onset of sick leave, on full and partial return to work.

Methods Altogether 853 public-sector employees in Sweden, mainly women, with at least one sick leave lasting $\geq 28$ days, were studied. The outcome was the level of sick leave 2 years after the sick leave began. Potential predictors were self-rated health, work ability, and psychosocial work conditions assessed by questionnaire before the sick leave. Odds ratios (OR) and $95 \%$ confidence intervals (95\% CI) were calculated by multinomial regression analyses.

Results Altogether $41 \%$ of the participants went directly from full sick leave to full return to work; $21 \%$ had periods of partial return to work, but, at the 2-year follow-up, were fully back to work; $15 \%$ had partial return to work; and $23 \%$ were still not working. A relaxed work situation, a combination of low demands and high decision latitude, increased the odds ratios for full (OR 2.72, 95\% CI 1.60-4.62) and partial (OR 2.42, 95\% CI 1.21-4.85) return to work. Negative consequences of organizational changes were associated with decreased odds ratios for full return to work (OR $0.54,95 \%$ CI $0.38-0.77$ ). Good self-rated health and work ability were associated with full return to work.

Conclusions Partial return to work often precedes full return to work, but also operates as a long-term solution for remaining occupationally active. Promoting relatively low demands and high decision latitude at work may support both full and partial return to work after long sick leaves.
\end{abstract}

Key terms partial sick leave; psychosocial work conditions; questionnaire; return to work; sick leave.

Partial return to work after an initial period of full-time sick leave has become more common in Sweden during recent years (1). The expectations of partial return to work are that employees with reduced work ability can return to active work and that partial return to work will promote and lead to earlier full return to work. However, we found only a few scientific studies concerning partial return to work (2-6).

Obviously, return to work after sickness absence is related to health and work ability. Self-rated health during the first months of a period of long-term sickness absence can be used as a predictor of return to work (7). In addition, the sick-listed person's own expectations of future work ability are strongly related to return to work $(8,9)$. However, return to work after a sick leave is influenced by several other conditions, for example, economic factors, workplace conditions, psychological factors, and social factors (10-14).

Few studies have differentiated between conditions that influence full and partial return to work. A crosssectional study by Johansson et al (5) identified an association between opportunities for work adjustment (ie, choosing among worktasks, influence over workpace and flexible workhours) on full and partial return to work separately. A questionnaire study of women with the chronic disease fibromyalgia concluded that reduced and flexible workhours made it possible for the women to remain in active work (3).

1 Occupational and Environmental Medicine, Uppsala University, Uppsala, Sweden.

2 Section of Personal Injury Prevention, Karolinska Institutet, Stockholm, Sweden.

3 Institute of Environmental Medicine, Karolinska Institutet, Stockholm, Sweden.

4 Stockholm Center of Public Health, Karolinska University Hospital, Stockholm, Sweden.

Correspondence to: Dr M Josephson, Occupational and Environmental Medicine, Uppsala University, Akademiska sjukhuset, 75185 Uppsala, Sweden. [E-mail: Malin.Josephson@medsci.uu.se] 
A cross-sectional questionnaire study of 1128 sicklisted employees in the public sector in Sweden revealed a positive attitude towards part-time sick leave. Almost all of those on part-time sick leave believed that it was good for them, and a majority expected that, within a year, they would still be on part-time sick leave. Of those who were sick-listed full-time, most believed that they would have benefited from part-time sick leave (6). Janssen et al (4) showed that high demands, reported before the onset of sick leave, predicted partial return to work. On the other hand, high demands were identified as an obstacle to full return to work. The follow-up period from the onset of sick leave was 4 months, and the study population consisted of employees in private companies, mainly men.

According to previous reports published in Swedish, persons who are partially sick-listed have often had long periods of full-time sick leave, partial sick leave is more frequent among women than among men, those who are sick-listed mostly perceive partial sick leave as positive, and almost all stakeholders believe that partial sick leave leads to earlier full return to work $(2,15)$.

The aim of our present study was to describe the frequency of full, partial, and no return to work 2 years after the onset of full-time long-term sick leave. An additional aim was to ascertain the influence of psychosocial work conditions, work ability, and health, reported before the onset of full-time sick leave, on full and partial return to work. The study group included mainly women, and the follow-up time from the onset of sick leave was 2 years. The study was carried out within the framework of the longitudinal study "Work and Health in the Public Sector in Sweden" (the HAKuL study) (16).

\section{Study population and methods}

The HAKuL study was launched in 1999-2000 in four county councils and among local authorities in six municipalities, covering the southern, middle, and northern parts of Sweden. Altogether, about 9000 persons were asked to participate, of whom $81 \%$ were women. The participating organizations were strategically chosen in collaboration with the national and local employer organizations and unions in order to cover different parts of the country, as well as different areas of activities in the public sector.

The study started with a postal baseline questionnaire on individual factors, social situation, health, lifestyle, and work factors being sent to all employees. Those who had been sick-listed for $\geq 3$ months at the time of the baseline questionnaire did not participate in the survey.

Data on sick leaves of $\geq 28$ days were collected and recorded via continuous contact with the studied workplaces and their supervisors. Information was compiled regarding dates for the onset of sick leave, dates for full return to work, periods of partial return to work, new periods of full-time sick leave, and level of sick leave 2 years after the sick-leave period began.

The study group of our present investigation was a subsample of the employees in the HAKuL study who were employed when the study started, had at least one continuous full-time sick leave lasting $\geq 28$ days during the next 3 years, and at the time of the onset of their sick-listing were younger than 63 years of age (1202 persons in all). The dropout rate, due to not responding to the questionnaire (234 persons), terminating their employment contract after the onset of long-term sickness absence (72 persons), and lack of information concerning return to work (42 persons) was $29 \%$.

The actual study group consisted of 853 employees who had at least one sick leave lasting $\geq 28$ days during a 3-year period. Most of them (84\%) had one full sickleave lasting at least 28 days during the follow-up period, and $16 \%$ had 2-3 full sick leaves. Of the 853 sicklisted persons, $89 \%$ were women, their mean age was 48 years, and 53\% were 50 years of age or older at the onset of their sick leave. The main occupational groups were assistant nurses, home-based personal care workers in elderly care, and registered nurses (table 1).

\section{Outcome variable}

The measured outcome in the study was the returnto-work status 2 years after the onset of a period of at least 28 days of full-time sick leave: full return to work, partial return to work, or no return to work (ie, full-time sick leave or disability retirement).

Table 1. Distribution of occupations in the study group.

\begin{tabular}{lrr}
\hline Occupation & $\begin{array}{r}\text { Women } \\
(\mathrm{N})\end{array}$ & $\begin{array}{c}\text { Men } \\
(\mathrm{N})\end{array}$ \\
\hline Home-based personal care worker in elderly care & 137 & 2 \\
Assistant nurse & 156 & 5 \\
Care assistant in social care & 86 & 15 \\
Registered nurse & 110 & 1 \\
Preschool teacher & 44 & 1 \\
Primary and secondary school teacher & 36 & 7 \\
Child care worker & 41 & - \\
Cleaner and kitchen staff & 36 & - \\
Medical secretary and administration assistant & 34 & - \\
Manager & 23 & 2 \\
Psychologist and social worker & 17 & 2 \\
Physician & 3 & 9 \\
Physical therapist and occupational therapist & 9 & 1 \\
Craftsman & - & 8 \\
Other & 45 & 23 \\
\hline Total & 777 & 76 \\
\hline
\end{tabular}




\section{Potential predictors}

Self-rated health, work ability, and psychosocial work conditions were assessed by a questionnaire before the onset of sick leave.

Physical and mental demands at work that were related to the employee's own capacity were measured by questions from the questionnaire concerning the work ability index (17). General health was assessed by the following item: "In general, how would you describe your health? As very good, good, neither good nor poor, poor, or very poor?" The response alternatives "very good" and "good" were classified as "good general health".

The job demand-control model was assessed by a Swedish version of the Job Content Questionnaire (18, 19). Five items were used to estimate mental workload, and six items covered decision latitude. In this study, a score of 14-20 for mental demands was considered as "high demands", and a score of 6-17 for decision latitude was considered as "low decision latitude". An index of social support at the workplace included six items, and a score of 13-22 was considered as "low social support" (20). Organizational changes at work the year before the baseline and the consequences of the changes were assessed by items used in the Swedish MOA study (21), with some adaptations to the current study group. The changes at work that were asked about were workload, time pressure, work requirements, opportunities to develop and learn new things, support, cooperation, influence and control, downsizing, job security, and involvement. Negative consequences of changes at work that were experienced were "not being able to perform work as well as I would like to", "not certain my competence is sufficient", "maybe the demands will be too high", "there will be conflicts at work", or "maybe I will lose my job". Those reporting three or more negative consequences were classified as experiencing negative consequences of changes at work. Poor leadership and a tendency towards social exclusion (bullying) at the workplace were assessed by single items.

\section{Additional factors}

Age, gender, level of occupational skill, the disorder resulting in sickness absence, and compounded rehabilitation measures (ie, a rehabilitation program 4 hours/day at least 4 days/week or a combination of physiotherapy, psychotherapy, and work-related vocational measures) (4) were also considered in the analyses. The rehabilitation measures were considered to be an indicator of the severity of the illness.

The occupational health services, the rehabilitation clinic, or the person on sick leave reported the disorders that resulted in sickness absence. The most common symptoms and disorders were musculoskeletal problems, especially neck-shoulder pain, low-back pain and osteoarthritis or other joint problems, and mental distress, especially depression and burnout syndromes.

The disorders were divided into the following three main categories: (i) musculoskeletal disorders, (ii) mental disorders, and (iii) other disorders. Participation in rehabilitation measures was interpreted as an indicator of the severe degree of the illness and was adjusted for in the multivariate analyses.

The level of occupational skill was classified according to the International Standard Classification of Occupations (ISCO-88). The occupations were stratified into the following three skill levels: occupations requiring at least 4 years of academic education after upper secondary school (ISCO level 4), occupations requiring at least 2 years of education after upper secondary school (ISCO level 3), and occupations requiring less education (ISCO-level 1,2).

\section{Statistical analyses}

Descriptive data on the occurrence of partial and full return to work in different stratums are presented as proportions with $95 \%$ confidence intervals $(95 \% \mathrm{CI})$. Multinomial logistic regression analyses, as well as univariate and multiple analyses, were carried out with outcome at the following three levels: full-time return to work, partial return to work, and not in work 2 years after the onset of full-time sick leave. The following factors were included in the multivariable regression analyses: gender, age, disorders, rehabilitation measures, occupational level, and the independent variables that, according to the univariate analyses, showed significant estimates (the 95\% CI of the OR did not include 1.00). The presented odds ratios (OR) with $95 \%$ confidence intervals represent the odds for full return to work and partial return to work among the exposed persons, compared with the odds among the unexposed persons.

\section{Results}

Of the 853 employees who had at least one continuous full-time sick leave lasting $\geq 28$ days, $41 \%$ had gone directly from full sick leave to full return to work, $21 \%$ had had periods of partial return to work but were fully back to work 2 years after the onset of their sick leave, $15 \%$ had partially returned to work, and $23 \%$ were still not working. Of the 347 persons (41\%) who had had periods of partial return to work, 41 were back on fulltime sick leave.

Full or partial return to work was reported for $83 \%$ of those aged $22-39$ years, for $75 \%$ in the 40 - to 59 -year 
age group, and for $85 \%$ of those aged 60 years or older. The proportion of partial return to work increased with age, $11.3 \%$ of those aged $22-49$ years and $18.7 \%$ of those aged 50 years or older (table 2).

Partial return to work was the most common in occupations requiring at least 2 years of education after upper secondary school; $20 \%$ had partially returned to work compared with $13 \%$ of those in occupations requiring less education (table 2).

With respect to disorders, $74 \%$ of those with musculoskeletal disorders, $77 \%$ of those with mental disorders, and $85 \%$ of those with other disorders were back at work fully or partially. The lowest rate of full return to work (56\%) was observed for those with mental disorders. On the other hand, those with mental disorders had the highest rate (21\%) of partial return to work. Of the study group, $4 \%$ had not returned to work, either fully or partially, and had not participated in rehabilitation measures (table 2).

A combination of relatively low demands and high decision latitude at work, reported by $23 \%$ before the onset of sick leave, increased the odds ratio both for full return to work (OR 2.72, 95\% CI 1.60-4.62) and for partial return to work (OR 2.42, 95\% CI 1.21-4.85). Negative consequences of organizational changes were associated with decreased odds for full return to work (OR 0.54, 95\% CI 0.38-0.77), but not for partial return to work. Bullying, social support, and poor leadership reported before the onset of sick leave were not associated with full or partial return to work in relation to no return to work (table 3 ).

Good general health, reported by $63 \%$ before the onset of sick leave, increased the odds ratio for full return to work (OR 2.16, 95\% CI 1.54-3.03), but not for partial return to work (OR 1.35, 95\% CI 0.86-2.11). Good physical and mental work ability before the onset of sick leave showed the same pattern; it increased the odds ratio for full return to work, but not for partial return to work (table 3 ).

\section{Multiple regression models}

A combination of relatively low demands and high decision latitude at work implied increased odds for both full and partial return to work, even when the analysis was adjusted for age, gender, disorders, rehabilitation measures, and level of occupational skill. When the model was additionally adjusted for self-reported health, work ability, and negative consequences of organizational changes, the directions of the estimates remained, but the estimated odds ratios were diluted. Negative consequences of organizational changes and good general health remained as significant factors for full return to work (table 4).

Table 2. Descriptive data of full, partial, or no return to work recorded 2 years after the onset of at least 28 days of full-time sickness absence, with respect to age, gender, level of occupational skill, disorders, and rehabilitation measures. $(95 \% \mathrm{Cl}=95 \%$ confidence interval)

\begin{tabular}{|c|c|c|c|c|c|c|c|}
\hline & \multirow[t]{2}{*}{ Number } & \multicolumn{2}{|c|}{ Full return to work } & \multicolumn{2}{|c|}{ Partial return to work } & \multicolumn{2}{|c|}{ No return to work } \\
\hline & & Proportion (\%) & $95 \% \mathrm{Cl}$ & Proportion (\%) & $95 \% \mathrm{Cl}$ & Proportion (\%) & $95 \% \mathrm{Cl}$ \\
\hline All participants & 853 & 62.1 & $58.8-65.3$ & 15.2 & $12.9-17.8$ & 22.6 & $20.0-25.6$ \\
\hline \multicolumn{8}{|l|}{ Age } \\
\hline $\begin{array}{l}22-39 \text { years } \\
40-49 \text { years } \\
50-59 \text { years } \\
60-62 \text { years }\end{array}$ & $\begin{array}{r}162 \\
237 \\
388 \\
66\end{array}$ & $\begin{array}{l}75.9 \\
60.3 \\
56.9 \\
65.1\end{array}$ & $\begin{array}{l}68.8-81.8 \\
53.9-66.3 \\
51.9-61.7 \\
53.1-75.5\end{array}$ & $\begin{array}{r}7.4 \\
13.9 \\
18.5 \\
19.7\end{array}$ & $\begin{array}{c}4.3-12.5 \\
10.1-18.9 \\
15.0-22.7 \\
11.8-30.8\end{array}$ & $\begin{array}{l}16.7 \\
25.7 \\
24.5 \\
15.2\end{array}$ & $\begin{array}{c}11.7-23.2 \\
20.6-31.7 \\
20.5-29.0 \\
8.4-25.7\end{array}$ \\
\hline \multicolumn{8}{|l|}{ Gender } \\
\hline $\begin{array}{l}\text { Female } \\
\text { Male }\end{array}$ & $\begin{array}{r}777 \\
76\end{array}$ & $\begin{array}{l}61.2 \\
71.0\end{array}$ & $\begin{array}{l}57.8-64.6 \\
60.0-80.0\end{array}$ & $\begin{array}{l}15.3 \\
14.4\end{array}$ & $\begin{array}{c}12.9-18.0 \\
8.2-24.0\end{array}$ & $\begin{array}{l}23.4 \\
14.5\end{array}$ & $\begin{array}{c}20.6-26.5 \\
8.3-24.1\end{array}$ \\
\hline \multicolumn{8}{|c|}{ Level of occupational skill } \\
\hline $\begin{array}{l}\text { Low } \\
\text { Medium } \\
\text { High }\end{array}$ & $\begin{array}{l}558 \\
147 \\
148\end{array}$ & $\begin{array}{l}63.0 \\
60.5 \\
60.1\end{array}$ & $\begin{array}{l}59.0-66.9 \\
52.4-68.0 \\
52.0-67.6\end{array}$ & $\begin{array}{l}12.5 \\
19.7 \\
20.9\end{array}$ & $\begin{array}{l}10.0-15.5 \\
14.1-26.9 \\
15.1-28.2\end{array}$ & $\begin{array}{l}24.4 \\
19.7 \\
18.9\end{array}$ & $\begin{array}{l}21.0-28.1 \\
14.1-26.9 \\
13.4-25.9\end{array}$ \\
\hline \multicolumn{8}{|l|}{ Disorders } \\
\hline $\begin{array}{l}\text { Musculoskeletal } \\
\text { Mental } \\
\text { Other }\end{array}$ & $\begin{array}{l}389 \\
262 \\
202\end{array}$ & $\begin{array}{l}61.1 \\
56.1 \\
71.7\end{array}$ & $\begin{array}{l}56.2-65.8 \\
50.0-61.9 \\
65.2-77.5\end{array}$ & $\begin{array}{l}12.8 \\
20.6 \\
12.8\end{array}$ & $\begin{array}{c}9.8-16.4 \\
16.1-25.9 \\
8.9-18.1\end{array}$ & $\begin{array}{l}26.0 \\
23.3 \\
15.4\end{array}$ & $\begin{array}{l}21.9-30.5 \\
18.6-28.8 \\
11.0-20.9\end{array}$ \\
\hline \multicolumn{8}{|l|}{ Rehabilitation } \\
\hline $\begin{array}{l}\text { Combined }{ }^{\mathrm{a}} \\
\text { Not combined }\end{array}$ & $\begin{array}{l}536 \\
317\end{array}$ & $\begin{array}{l}50.4 \\
82.0\end{array}$ & $\begin{array}{l}46.1-54.5 \\
77.4-85.8\end{array}$ & $\begin{array}{r}20.1 \\
6.9\end{array}$ & $\begin{array}{c}16.9-23.7 \\
4.5-10.4\end{array}$ & $\begin{array}{l}29.8 \\
11.0\end{array}$ & $\begin{array}{c}25.8-33.5 \\
8.1-15.0\end{array}$ \\
\hline
\end{tabular}

${ }^{a}$ A combination of physiotherapy, psychotherapy, and vocational measures. 
Table 3. Odds ratios $(\mathrm{OR})$ with $95 \%$ confidence intervals $(95 \% \mathrm{Cl})$ for full return to work and partial return to work compared with no return to work, in relation to the self-reported independent variables assessed before the onset of the sick-leave period-calculated by univariate multinomial logistic regression analyses.

\begin{tabular}{|c|c|c|c|c|c|c|c|}
\hline \multirow[t]{2}{*}{ Independent variable } & \multirow[t]{2}{*}{$\mathrm{N}$} & \multicolumn{3}{|c|}{ Full return to work } & \multicolumn{3}{|c|}{ Partial return to work } \\
\hline & & $\mathrm{N}$ & $\mathrm{OR}$ & $95 \% \mathrm{Cl}$ & N & $\mathrm{OR}$ & $95 \% \mathrm{Cl}$ \\
\hline \multicolumn{8}{|l|}{ Demand-control model } \\
\hline High demands-low decision latitude & 217 & 127 & 1 & & 30 & 1 & \\
\hline High demands-high decision latitude & 188 & 109 & 1.07 & $0.68-1.70$ & 31 & 1.29 & $0.69-2.42$ \\
\hline Low demands-low decision latitude & 222 & 134 & 1.17 & $0.76-1.82$ & 34 & 1.26 & $0.68-2.33$ \\
\hline Low demands-high decision latitude & 191 & 138 & 2.72 & $1.60-4.62$ & 29 & 2.42 & $1.21-4.85$ \\
\hline Negative consequences of changes ${ }^{a}$ & 263 & 138 & 0.54 & $0.38-0.77$ & 49 & 0.95 & $0.59-1.51$ \\
\hline Bullying a & 168 & 100 & 0.93 & $0.61-1.41$ & 30 & 1.21 & $0.70-2.07$ \\
\hline Poor leadership a & 230 & 143 & 1.02 & $0.70-1.49$ & 36 & 1.03 & $0.63-1.70$ \\
\hline Poor social supporta & 233 & 153 & 1.36 & $0.92-2.011$ & 37 & 1.38 & $0.82-2.31$ \\
\hline Good general health a & 536 & 363 & 2.16 & $1.54-3.03$ & 75 & 1.35 & $0.86-2.11$ \\
\hline $\begin{array}{l}\text { Physical demands at work in balance } \\
\text { with the individual's capacity a }\end{array}$ & 583 & 387 & 2.01 & $1.43-2.84$ & 85 & 1.46 & $0.92-2.32$ \\
\hline $\begin{array}{l}\text { Mental demands at work in balance } \\
\text { with the individual's capacity a }\end{array}$ & 602 & 389 & 1.51 & $1.06-2.15$ & 88 & 1.17 & $0.73-1.88$ \\
\hline
\end{tabular}

a Exposed compared with others.

Table 4. Odds ratios $(\mathrm{OR})$ and $95 \%$ confidence intervals $(95 \% \mathrm{Cl})$ for full return to work and partial return to work compared with no return to work, in relation to the independent variables reported before the onset of sick leave—calculated by multiple multinomial logistic regression analyses.

\begin{tabular}{|c|c|c|c|c|c|c|c|c|}
\hline \multirow[t]{3}{*}{ Independent variable (exposure) } & \multicolumn{4}{|c|}{ Model $1^{\mathrm{a}}$} & \multicolumn{4}{|c|}{ Model $2^{b}$} \\
\hline & \multicolumn{2}{|c|}{ Full return to work } & \multicolumn{2}{|c|}{ Partial return to work } & \multicolumn{2}{|c|}{ Full return to work } & \multicolumn{2}{|c|}{ Partial return to work } \\
\hline & $\mathrm{OR}$ & $95 \% \mathrm{Cl}$ & $\mathrm{OR}$ & $95 \% \mathrm{Cl}$ & $\mathrm{OR}$ & $95 \% \mathrm{Cl}$ & $\mathrm{OR}$ & $95 \% \mathrm{Cl}$ \\
\hline Low demands-high decision latitude ${ }^{c}$ & 2.45 & $1.50-4.00$ & 1.91 & $1.04-3.51$ & 1.88 & $1.12-3.15$ & 1.75 & $0.92-3.33$ \\
\hline Negative consequences of changes ${ }^{c}$ & 0.53 & $0.36-0.77$ & 0.84 & $0.52-1.36$ & 0.64 & $0.42-0.96$ & 0.93 & $0.55-1.57$ \\
\hline Good general health ${ }^{c}$ & 2.09 & $1.47-2.98$ & 1.32 & $0.84-2.07$ & 1.60 & $1.04-2.45$ & 1.23 & $0.71-2.13$ \\
\hline $\begin{array}{l}\text { Physical demands at work in balance } \\
\text { with the individual's capacity c }\end{array}$ & 1.83 & $1.28-2.63$ & 1.41 & $0.88-2.27$ & 1.39 & $0.88-2.22$ & 1.12 & $0.61-2.04$ \\
\hline $\begin{array}{l}\text { Mental demands at work in balance } \\
\text { with the individual's capacity c }\end{array}$ & 1.64 & $1.12-2.39$ & 1.29 & $0.78-2.10$ & 0.94 & $0.59-1.50$ & 1.05 & $0.57-1.93$ \\
\hline
\end{tabular}

${ }^{a}$ Model 1: included one of the independent variables presented in the table and was adjusted for gender, age, disorders, rehabilitation measures, and level of occupational skill.

${ }^{\mathrm{b}}$ Model 2: included all of the independent variables presented in the table and was adjusted for gender, age, disorders, rehabilitation measures, and level of occupational skill.

${ }^{c}$ Exposed compared with others.

\section{Discussion}

In this study of public-sector employees who had a sickleave lasting at least 28 days, $77 \%$ had fully or partially returned to work 2 years after the onset of the sick leave. Most of those who had periods of partial sick leave were fully back at work at the time of the 2-year follow-up. The results support the assumption that psychosocial work conditions influence opportunities for full and partial return to work. Good self-rated health and work ability, before the onset of sick leave, were mainly associated with full return to work.

At the 2-year follow-up, an increased chance of full or partial return to work was associated with a relaxed work situation, a combination of relatively low demands, and high decision latitude at work. High demands were obstacles for return to work when compared with a relaxed work situation. Return to work can be considered a process with different phases (ie, work re-entry) followed by the retention of work (22). In some situations, high demands may prompt early partial return to work, as in the study of Jansen et al (4), but for the retention of work and full return to work, a high degree of influence over the work situation, combined with not too high demands, can be crucial.

High-strain jobs (ie, high demands in combination with low decision latitude) cause health problems, according to the job strain hypothesis, especially in 
contrast with relaxed jobs, often used as a reference category in studies of the relation between job stress and health problems (23). A study of Lidwall \& Marklund (24) confirmed that high-strain jobs increase the risk of long-term sickness absence in both the public and private sector in Sweden. Consequently, promoting relatively low demands and high decision latitude at work seems both to prevent long-term sick leave and to support return to work after long sick leaves.

Negative consequences of organizational changes at work were associated with a decreased probability of full return to work. Previous studies from the HAKuL project show that negative consequences of organizational changes also increase the risk of long-term sick leave and of terminating an employment contract (16, 25).

The odds for partial return to work were not influenced by negative consequences of organizational changes. In addition, good work ability and good selfreported health, before the onset of sick leave, revealed a marked association with full return to work, but not with partial return to work. The weaker associations with partial return to work indicate that other factors, work-related or not, are more important for partial return to work.

In agreement with previous data $(2,15)$, partial return to work was less frequent in occupations not requiring a high level of education, such as home-based personal care and assistant nursing in geriatric care. Employees with a lower employment grade, often with physically demanding work, have a relatively high rate of long-term sick leave (26). The supply of nursing personnel is, in many countries, a public health problem, and the retention of nurses is a considerable challenge to health care management and organizations (27-29). Partial return to work implies less exposure time and may enable those with reduced work ability to remain in their physically demanding occupations.

In line with the idea that partial return to work promotes full return to work, the probability of achieving full return to work should be increased in occupations requiring a high level of education. Unexpectedly, after 2 years, a high level of occupational skill implied an increased frequency for partial return to work, but not for full return to work. The opportunity of partial sick-listing may lead to a higher frequency of return to work but also to a risk of prolonged partial sick-listing. On the other hand, mental illness is a common cause of long-term sick leave, and occupations with a high level of skill require a sustainable mental work capacity. Recovering from a mental disorder is often a prolonged process, and getting back to full work capacity can be a process that takes longer than 2 years.

Partial return to work was often a part of the rehabilitation process, and, in this study, for those who had had a limited period of partial return to work, it was a step towards full return to work. However, for many of those who were still partially sick-listed after 2 years, partial return to work may have been in balance with both their current and future work ability and was not a step forward towards full return to work. Partial return to work can be considered a long-term opportunity for those with reduced work ability to remain in active work.

\section{Study design}

The data on sick-leave of $\geq 28$ days were recorded by means of continuous contact with the studied workplaces and their supervisors, not from register data. There was probably an underreporting of cases with sick-leave periods not far from the cutoff point. However, the cutoff point of 4 weeks is likely to have increased the validity of the collected data (ie, that most of the cases were reported) because, after 4 weeks of sick leave, the employer was required to act and consider a plan for return to work.

The prospective cohort design (ie, the information about work conditions gathered before the onset of sick leave) made it possible to study the temporal relationship between exposure and return to work. This possibility also implied that the risk for recall bias due to absence from work, health status, motivation, and success of return to work was reduced. On the other hand, we had no information about changes in work conditions at the workplace. In some cases the questionnaire was answered some days before the onset of sick leave, and in other cases it was answered nearly 3 years before the period of sick leave. A long period between exposure measurements and outcome may have led to an underestimation of the effect of exposure. We adjusted the analyses for the time between the questionnaire and sick-listing but saw no marked differences in the associations. An interpretation of the observed association between work conditions and return to work is that psychosocial work conditions are rather stable.

Another limitation is that the study did not take into account the duration of the sick leave within the followup period. The length of sick leave is generally seen as a predictive factor for full return to work. For partial return to work, the situation is more complex. Those who are partially sick-listed have often had long periods of full-time sick leave, repeated periods of sick leave, and long-term health problems (2). The 2-year follow-up period probably made it possible to capture those with long-term reduced work ability who had been given the opportunity to return to work with reduced workhours.

There are some limitations with regard to generalizing the findings, since the selection of participating county councils and local authorities was not random. A long-standing commitment to the study was needed 
because it was necessary for the organizations to help with the following aspects: administration of questionnaires, receiving feedback from the surveys, involvement in the rehabilitation measures, and reporting of employees on long-term sick leave. However, the cohort represented all kinds of activities performed by county councils and municipalities in different parts of Sweden, including both rural and urban areas, although there was some predominance of home care and health care workers. In addition, the age and gender distribution in this study was representative of employees in Swedish municipalities and county councils in general (16). The investigation was part of the HAKuL project, including interventions at the workplace and rehabilitation measures. This situation may have implied a dilution of the association of conditions reported before the onset of full-time sick leave and return to work.

\section{Concluding remarks and implications}

Partial return to work often precedes full return to work but also operates as a long-term solution for remaining in active work. Promoting relatively low demands and high decision latitude at work may prevent long-term sick leave and support return to work after long sick leaves. In health and social care work, partial return to work may enable those with a reduced ability to remain in their physically demanding occupations.

\section{Acknowledgments}

This study was funded by the Swedish Council for Working Life and Social Research, and by AFA Labour Market Insurance.

\section{References}

1. Swedish Social Insurance Agency. Social insurance in Sweden [homepage on the Internet]. Stockholm: Swedish Social Insurance Agency [updated May 20, 2008 cited June 2008]. Available from: http://uppsol.forsakringskassan.se/ templates/Page. aspx?id=2611

2. Eklund M, von Granitz H, Marklund S. Deltidssjukskrivningindivid, arbetsplats och hälsa [Part-time sickness absence-individual, workplace and health]. In: Hogstedt C, Bjurvald M, Marklund S, Palmer E, Theorell T, editors. Den höga sjukfrånvaron-sanning och konsekvens [The high incidence of sickness absence-facts and consequences]. Stockholm: Statens folkhälsoinstitut; 2004. p 83-121.

3. Henriksson CM, Liedberg GM, Gerdle B. Women with fibromyalgia: work and rehabilitation. Disabil Rehabil. 2005;27(12):685-94.

4. Janssen N, van den Heuvel WP, Beurskens AJ, Nijhuis
FJ, Schroer CA, van Eijk JT. The demand-control-support model as a predictor of return to work. Int J Rehabil Res. 2003;26(1):1-9.

5. Johansson G, Lundberg O, Lundberg I. Return to work and adjustment latitude among employees on long-term sickness absence. J Occup Rehabil. 2006;16(2):185-95.

6. Sieurin L, Josephson M, Vingard E. Positive and negative consequences of sick leave for the individual, with special focus on part-time sick leave. Scand J Public Health. In press.

7. Post M, Krol B, Groothoff JW. Self-rated health as a predictor of return to work among employees on long-term sickness absence. Disabil Rehabil. 2006;28(5):289-97.

8. Hansen A, Edlund C, Henningsson M. Factors relevant to a return to work: a multivariate approach. Work. 2006;26(2):17990.

9. Heijbel B, Josephson M, Jensen I, Stark S, Vingard E. Return to work expectation predicts work in chronic musculoskeletal and behavioral health disorders: prospective study with clinical implications. J Occup Rehabil. 2006;16(2):173-84.

10. Krause N, Dasinger LK, Deegan LJ, Rudolph L, Brand RJ. Psychosocial job factors and return-to-work after compensated low back injury: a disability phase-specific analysis. Am J Ind Med. 2001;40(4):374-92.

11. Krause N, Frank JW, Dasinger LK, Sullivan TJ, Sinclair SJ. Determinants of duration of disability and return-to-work after work-related injury and illness: challenges for future research. Am J Ind Med. 2001;40(4):464-84.

12. Labriola M, Lund T, Christensen KB, Kristensen TS. Multilevel analysis of individual and contextual factors as predictors of return to work. J Occup Environ Med. 2006;48(11):1181-8.

13. Lund T, Labriola M, Christensen KB, Bultmann U, Villadsen E. Return to work among sickness-absent Danish employees: prospective results from the Danish Work Environment Cohort Study/National Register on Social Transfer Payments. Int J Rehabil Res. 2006;29(3):229-35.

14. Post M, Krol B, Groothoff JW. Work-related determinants of return to work of employees on long-term sickness absence. Disabil Rehabil. 2005;27(9):481-8.

15. Riksförsäkringsverket. Långtidssjukskrivna—diagnos, yrke, partiell sjukskrivning och återgång i arbete [Long-term sicklisted-diagnosis, occupation, partial sick-listing and returnto-work]. Stockholm: Riksförsäkringsverket; 2004. Report no 7.

16. Vingård E, Lindberg $\mathrm{P}$, Josephson $\mathrm{M}$, Voss $\mathrm{M}$, Heijbel B, Alfredsson L, et al. Long-term sick-listing among women in the public sector and its associations with age, social situation, lifestyle and work factors: a three-year follow-up study. Scand J Public Health. 2005;33(5):370-5.

17. Tuomi K, Ilmarinen J, Jahkola A, Katajarinne L, Tulkki A. Work ability index. Helsinki: Finnish Institute of Occupational Health; 1994.

18. Karasek RA, Theorell T. Healthy work. New York (NY): Basic Books; 1990.

19. Waldenström M, Theorell T, Ahlberg G, Svensson H, Josephson $\mathrm{M}$, Johansson $\mathrm{K}$, et al. Assessment of psychological and social current working conditions in the MUSIC-Norrtälje Study. Scand J Public Health. 2002;30:94-102.

20. Toomingas A, Theorell T, Michélsen H, Nordemar R, Stockholm Music I Study Group. Associations between self-rated psychosocial work conditions and musculoskeletal symptoms and signs. Scand J Work Environ Health. 1997;23(2):130-9.

21. Härenstam A, Karlqvist L, Bodin L, Nise G, Schéele P, et al. Patterns of working and living conditions: a holistic, multivariate approach to occupational health studies. Work Stress. 
2003;17:73-92.

22. Young AE, Roessler RT, Wasiak R, McPherson KM, van Poppel MN, Anema JR. A developmental conceptualization of return to work. J Occup Rehabil. 2005;15(4):557-68.

23. de Lange AH, Taris TW, Kompier MA, Houtman ILD, Bongers PM. "The very best of the millennium": longitudinal research and the demand-control-(support) model. J Occup Health Psychol. 2003;8:282-305.

24. Lidwall U, Marklund S. What is healthy work for women and men?-a case-control study of gender- and sector-specific effects of psycho-social working conditions on long-term sickness absence. Work. 2006;27(2):153-63.

25. Josephson M, Lindberg P, Voss, M, Alfredsson L, Vingård E. The same factors influence job turnover and long spells of sick leave-a 3-year follow-up of Swedish nurses. Eur J Public Health. 2008;18(4):380-5.
26. Fuhrer R, Shipley MJ, Chantang JF, Schmaus A, Niedhammer I, Stansfeld SA, et al. Socioeconomic position, health, and possible explanations: a tale of two cohorts. Am J Public Health: 2002;92(8)1290-4.

27. Hasselhorn H-M, Müller BH, Tackenberg P. NEXT scientific report. Wüppertal (Germany): Wüppertal University; 2005.

28. Janiszewski Goodin H. The nursing shortage in the United States of America: an integrative review of the literature. J Adv Nurs. 2003;43:335-43.

29. Raeve PD. Commentary: a European perspective: comments to the article "The nursing shortage in the United States of America: an integrative review of the literature". J Adv Nurs. 2003;43:348-50.

Received for publication: 5 December 2007 